\title{
Knowledge, Games and Tales from the East
}

\author{
Rohit Parikh
}

\section{Brooklyn College of CUNY and CUNY Graduate Center}

October 10, 2008

Abstract: We introduce some basic concepts from Game Theory and related areas and show how various insights for which we thank game theory have already occurred in the past in some tales from ancient literature, both Indian and otherwise.

\section{Games}

We shall usually talk about two player games. The players are typically called Row and Column, but more catchy names may arise in specific contexts.

In so called normal form games, each player has a finite set of strategies, call them $S_{1}$ and $S_{2}$, and each can choose a particular strategy from their own set. Once the players have chosen their strategies, there are payoffs which depend on both the strategies. So suppose that player Row chooses strategy $a$ and Column chooses strategy $b$, then the payoffs would be $p_{r}(a, b)$ and $p_{c}(a, b)$. We may also refer to Row and Column as players 1 and 2 respectively.

Suppose Row has chosen $a$ and Column has chosen $b$, then $(a, b)$ constitutes a Nash equilibrium if, given that column is playing b, Row has nothing better than $a$, and given that Row is playing $a$, Column has nothing better than $b$. In other words $p_{r}(a, b) \geq p_{r}\left(a^{\prime}, b\right)$ for all $a^{\prime}$ and $p_{c}(a, b) \geq p_{c}\left(a, b^{\prime}\right)$ for all $b^{\prime}$. 
Given two strategies $a, a^{\prime}$ for Row, we say that $a$ is dominated by $a^{\prime}$ if regardless of what Column plays, $a^{\prime}$ always gives a better outcome for Row. Thus $p_{r}(a, b) \leq p_{r}\left(a^{\prime}, b\right)$ for all $b$ and $p_{r}(a, b)<p_{r}\left(a^{\prime}, b\right)$ for at least one $b$. Sinilarly for dominance of a Column strategy $b$ by $b^{\prime}$. It is normally accepted that a player would never play a dominated strategy, and the opponent may then make his plans based on this fact.

We now give examples of various games in the literature.

\subsection{Battle of the Sexes}

In this game, the wife (Row) wants to go to the Opera and the husband (Column) wants to watch football. But each would rather go together than watch their favourite thing by themselves. So here are the payoffs. Row's payoffs in each box are listed first.

\begin{tabular}{c|c|c|}
\multicolumn{1}{c}{} & \multicolumn{1}{c}{ Opera } & Footb \\
\cline { 2 - 3 } Opera & 2,1 & 0,0 \\
\cline { 2 - 3 } Footb & 0,0 & 1,2 \\
\cline { 2 - 3 } & &
\end{tabular}

If they go to different events, they are not happy so the payoffs are zero for both. If they go to the same event, then both have positive payoffs, but the wife's is higher if they go to the Opera and the husband's is higher if they go to football. There are two Nash equilibria, the NW one which is $(2,1)$, and the SE one which is $(1,2)$.

The fact that $(1,2)$ is a Nash equilibrium can be seen geometrically. Row can change the row, but if she does her payoff will move from 1 to 0 , and she will be worse off. Similarly, Column can change the column, but if he does, his payoff will change from 2 to 0 , and he will be worse off.

\subsection{Chicken}

In this rather dangerous game, two cars race towards each other. If one goes straight and the other swerves, then the one who swerves has shown fear, 
and is called chicken. He is embarrassed while the other crows. If neither swerves then there is an accident which they both regret - if they survive.

\begin{tabular}{c|c|c|} 
& \multicolumn{1}{c}{ Swerve } & \multicolumn{1}{c}{ Straight } \\
\cline { 2 - 3 } Swerve & 4,4 & 2,7 \\
\cline { 2 - 3 } Straight & 7,2 & $-10,-10$ \\
\cline { 2 - 3 } & &
\end{tabular}

There are two Nash equilibria, the NE one which is $(2,7)$, with Row being the 'chicken' and the SW one which is $(7,2)$ wth Column in that role.

\subsection{Matching Pennies}

\begin{tabular}{r|l|l|} 
& \multicolumn{1}{c}{ Heads } & \multicolumn{1}{c}{ Tails } \\
\cline { 2 - 3 } Heads & $1,-1$ & $-1,1$ \\
\cline { 2 - 3 } Tails & $-1,1$ & $1,-1$ \\
\cline { 2 - 3 } & &
\end{tabular}

In this game, Row is the matcher and Column is the mismatcher. Both parties exhibit a penny and if both pennies match (are both showing heads or both showing tails) then Row wins. If one is showing heads and the other tails (mismatch), then Column wins. There are no Nash equilibria in this game (there is a mixed strategy equilibrium, but we shall not consider those here).

\subsection{Prisoner's dilemma}

In this game, two men are arrested and invited to testify against each other. If neither testifies, then there is a small penalty since there is no real evidence. But if one defects (testifies) and the other does not, then the defecter goes free and the other gets a large sentence. If both defect they both get medium sentences. Jointly they are better off (The payoffs are 2 each) if neither defects, but for both of them, defecting is the dominant strategy and they end up with $(1,1)$ which is worse. 


\begin{tabular}{c|c|c|}
\multicolumn{1}{c}{} & \multicolumn{1}{c}{ Coop } & Def \\
\cline { 2 - 3 } Coop & 2,2 & 0,3 \\
\cline { 2 - 3 } Def & 3,0 & 1,1 \\
\cline { 2 - 3 } & &
\end{tabular}

There is a unique, rather bad Nash equilibrium at SE with $(1,1)$, while the $(2,2)$ solution on NW, though better for both, is not a Nash equilibrium.

We now discuss the first one of our folk examples. We start with an actual example from the Economics literature and then relate it to a story from Indian history.

\section{Tales from the East}

\subsection{Tragedy of the Commons}

From "The Tragedy of the Commons" by Garrett Hardin, 1968.

The tragedy of the commons develops in this way. Picture a pasture open to all. It is to be expected that each herdsman will try to keep as many cattle as possible on the commons. Such an arrangement may work reasonably satisfactorily for centuries because tribal wars, poaching, and disease keep the numbers of both man and beast well below the carrying capacity of the land. Finally, however, comes the day of reckoning, that is, the day when the long-desired goal of social stability becomes a reality. At this point, the inherent logic of the commons remorselessly generates tragedy.

As a rational being, each herdsman seeks to maximize his gain. Explicitly or implicitly, more or less consciously, he asks, "What is the utility to me of adding one more animal to my herd?" This utility has one negative and one positive component.

1. The positive component is a function of the increment of one animal. Since the herdsman receives all the proceeds from the sale of the additional animal, the positive utility is nearly +1 . 
2. The negative component is a function of the additional overgrazing created by one more animal. Since, however, the effects of overgrazing are shared by all the herdsmen, the negative utility for any particular decisionmaking herdsman is only a fraction of -1 .

Adding together the component partial utilities, the rational herdsman concludes that the only sensible course for him to pursue is to add another animal to his herd. And another.... But this is the conclusion reached by each and every rational herdsman sharing a commons. Therein is the tragedy. Each man is locked into a system that compels him to increase his herd without limit - in a world that is limited. Ruin is the destination toward which all men rush, each pursuing his own best interest in a society that believes in the freedom of the commons. Freedom in a commons brings ruin to all.

From "The Tragedy of the Commons" by Garrett Hardin, [4].

But Hardin was anticipated in India by four hundred years!

The following is from the famous Akbar Birbal collection of stories. Akbar was the third Mughal emperor and the grandfather of Shah Jehan who built the Taj Mahal as a monument (and mausoleum) for his wife. Birbal was one of his ministers and well known (at least in stories) for his wit and intelligence. Both lived in the second half of the sixteenth century.

\subsection{Birbal story:}

One day Akbar Badshah said something to Birbal and asked for an answer. Birbal gave the very same reply that was in the king's own mind. Hearing this, the king said, This is just what I was thinking also. Birbal said, Lord and Guide, this is a case of a hundred wise men, one opinion (in Hindi, sau siyane ek mat). The king said, This proverb is indeed well-known. Then Birbal petitioned, Refuge of the World, if you are so inclined, please test this matter. The king replied, Very good.

The moment he heard this, Birbal sent for a hundred wise men from the city. And the men came into the king's presence that night.

Showing them an empty well, Birbal said, His Majesty orders that at once every man will bring one bucket full of milk and pour it in this well. 
The moment they heard the royal order, every one reflected that where there were ninety-nine buckets of milk, how could one bucket of water be detected? Each one brought only water and poured it in. Birbal showed it to the king.

The king said to them all, What were you thinking, to disobey my order? Tell the truth, or I'll treat you harshly! Every one of them said with folded hands, Refuge of the World, whether you kill us or spare us, the thought came into this slave's mind that where there were ninety-nine buckets of milk, how could one bucket of water be detected?

Hearing this from the lips of all of them, the king said to Birbal, What I'd heard with my ears, I've now seen before my eyes: a hundred wise men, one opinion!

Birbal lived from 1528 to 1586, and died in the battle of Malandari Pass, in Northwest India.

http://en.wikipedia.org/wiki/Akbar_the_Great

http://en.wikipedia.org/wiki/Birbal

\section{Analysis:}

What is common between the example which Hardin gives and the AkbarBirbal story? In each case, the individual benefits at the cost of the group. In the Hardin case, the herdsman benefits by having one more animal. In the Birbal case, the "wise man" benefits by saving one pot of milk. In each case the group is harmed. In the case of the herdsmen, the common is overgrazed and the grass dies. In the Akbar-Birbal case, there is a danger that if the cheating is discovered, all hundred men face the threat of prison or even execution. Akbar was a benign king, ${ }^{1}$ but not entirely immune to anger.

Also, in each case, cheating is a dominant strategy. If most of the others are cheating, it does no extra harm if you cheat too. And if most of the others are not cheating, then again it does no extra harm if you are one of the rare cheaters. But if everyone practices their dominant strategy and cheats, then

\footnotetext{
${ }^{1}$ Akbar, though a Muslim, worked hard to create amity between Hindus and Muslims, even marrying a Hindu wife, and having endless discussions on religion with Hindus, Christians and Jains.
} 
there can be disaster for the whole group.

\subsection{Can we always believe what others tell us? Solomon story:}

The following story is from the Old Testament, first book of Kings, chapter 3 .

Then came there two women, that were harlots, unto the king, and stood before him.

And the one woman said, O my lord, I and this woman dwell in one house; and I was delivered of a child with her in the house.

And it came to pass the third day after that I was delivered, that this woman was delivered also: and we were together; there was no stranger with us in the house, save we two in the house.

And this woman's child died in the night; because she overlaid it.

And she arose at midnight, and took my son from beside me, while thine handmaid slept, and laid it in her bosom, and laid her dead child in my bosom.

And when I rose in the morning to give my child suck, behold, it was dead: but when I had considered it in the morning, behold, it was not my son, which I did bear.

And the other woman said, Nay; but the living is my son, and the dead is thy son. And this said, No; but the dead is thy son, and the living is my son. Thus they spake before the king.

Then said the king, The one saith, This is my son that liveth, and thy son is the dead: and the other saith, Nay; but thy son is the dead, and my son is the living.

And the king said, Bring me a sword. And they brought a sword before the king.

And the king said, Divide the living child in two, and give half to the one, and half to the other. 
Then spake the woman whose the living child was unto the king, for her bowels yearned upon her son, and she said, O my lord, give her the living child, and in no wise slay it. But the other said, Let it be neither mine nor thine, but divide it.

Then the king answered and said, Give her the living child, and in no wise slay it: she is the mother thereof.

\section{Analysis}

Let $\mathbf{M}$ stand for "I get the child", $\mathbf{O}$ stand for "The other woman gets the child", and K stand for "The child is killed.

Both women prefer $\mathbf{M}$ to $\mathbf{O}$. However, Solomon relies on the fact that the real mother prefers $\mathbf{O}$ to $\mathbf{K}$ whereas the non-mother prefers $\mathbf{K}$ to $\mathbf{O}$. Thus the orderings are:

$M>O>K$ for the real mother and $M>K>O$ for the non-mother. Asked to choose between $O$ and $K$, the real mother chooses $O$ and the non-mother chooses $K$. This enables Solomon to discover the real mother. Solomon is trying to implement what is called the revelation principle according to which people reveal their real opinions by how they act.

However, Solomon's strategy has a bug. If the non-mother knows what his plans are, all she has to do is to say, "Oh, I too would rather the other woman took the child than have it killed." And then Solomon would be in a quandary.

Such a behavior would be an example of what is called strategizing $[3,7,8]$, where you express a preference different from your actual one in order to get a better result.

There is, however, a solution which depends on money, or let us say, public service. Suppose the real mother is willing to do three months public service to get the child, but the non-mother is only willing to do one month. Solomon of course does not know which is which but he can use this information and the following procedure to discover who is the real mother.

Thus here is the plan. Suppose the two women are Anna and Beth. Solomon first asks Anna, Is the child yours? If Anna says no, Beth gets the child and that ends the matter. 
If Anna says, It is my child, then Beth is asked Is the child yours? If Beth says no, Anna gets the child and that ends the matter.

If Beth also says, It is my child, then Beth gets the child, and does two months public service. Anna also does one week's public service

It is easy to see that only the real mother will say, It is my child, and no public service needs to be performed.

For suppose that Anna is the real mother. She can safely say, It is my child because when Beth is asked next, she does not want to do two months service to get the child. Anna will get the child without any problem. I leave it to you to work out what happens if Beth is the real mother. For a recent paper on such problems, see

$$
\text { http://ideas.repec.org/p/pra/mprapa/8801.html }
$$

It might have struck the reader that while the outcome is fair to both women, the algorithm is not symmetric. But there do exist symmetric algorithms based on the idea of the Vickrey auction [5], and the one in the paper cited just above is an example.

\subsection{Cheap Talk}

The following examples are slightly adapted from [2]

Laxmi is applying to Rayco for a job, and Rayco asks if her ability is high or low.

Will Laxmi speak the truth, and can Rayco trust her? 


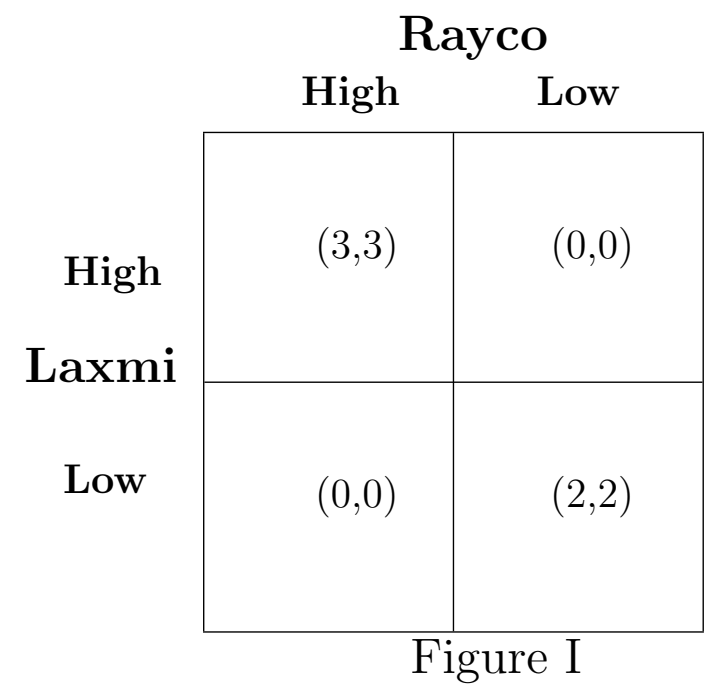

In the scenario above, Figure I, Rayco prefers to hire Laxmi for the high position if she has high ability and the low position if her ability is low. If they ask her about her ability, Laxmi has nothing to gain by lying about her qualifications and Rayco can trust her. In particular, if her ability is low and she lies that it is high, Rayco would give her the higher position and she would be frustrated so that the higher salary would not be an advantage.

But suppose instead (Figure II) that Laxmi feels she can get away with having a better job even with worse ability. Perhaps she feels she can 'wing it', or pass on her more difficult work to others. If Laxmi's ability is low, she still prefers the higher paying job so she would like to entice Rayco (which chooses the job she is offered) into the bottom left box. But if Rayco knows her payoffs, they will be careful not to believe her bare statement that she has high ability. 


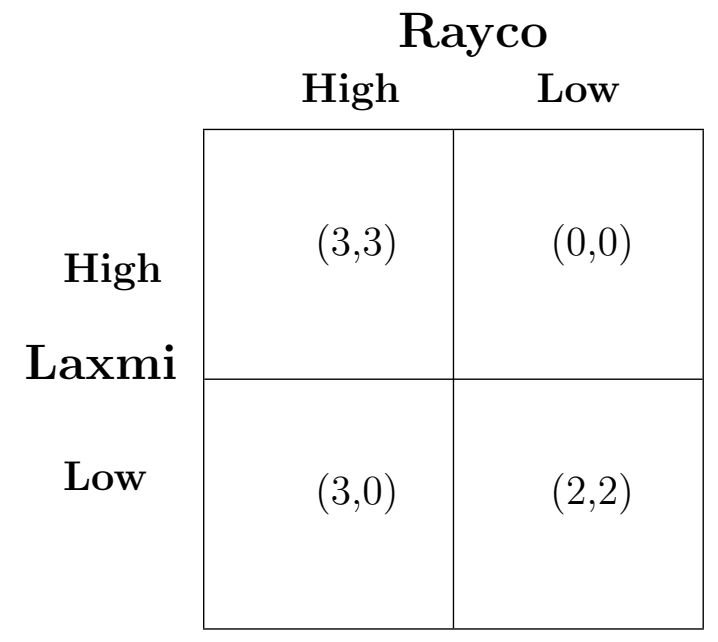

Figure II

In this scenario, Laxmi can profit from having a high job even if her ability is low, her payoff is 3 in any case. So Laxmi has nothing to lose by lying about her qualifications and Rayco cannot trust her.

The moral is, as we all know, If someone tells us something, then before believing it, ask if they could gain by lying. There is a bit more to cheap talk than this but we shall not go into details.

\subsection{The Mahabharata}

The Kurukshetra War forms an essential component of the Hindu epic Mahabharata. According to Mahabharata, a dynastic struggle between sibling clans of Kauravas and the Pandavas for the throne of Hastinapura resulted in a battle in which a number of ancient kingdoms participated as allies of the rival clans. The location of the battle was Kurukshetra in the modern state of Haryana in India.

Mahabharata states that the war lasted eighteen days during which vast armies from all over ancient India fought alongside the two rivals. Despite only referring to these eighteen days, the war narrative forms more than a quarter of the book, suggesting its relative importance within the book.

http://en.wikipedia.org/wiki/Kurukshetra_War 
During the war, Drona, who was the teacher of both Pandavas and Kauravas, and an expert bowman, is fighting on the side of the Kauravas and the Pandavas are desperate as they do not know what to do! Luckily, Drona's son is called Ashwathama as is an elephant owned by the Pandavas.

Yudhisthira was the oldest of the five Pandava brothers, and had a reputation for honesty. His role in what happens is crucial.

On the 15th day of the war. Krishna asked Yudhisthira to proclaim that Drona's son Ashwathama has died, so that the invincible and destructive Kuru commander would give up his arms and thus could be killed. Bhima proceeds to kill an elephant named Ashwathama, and loudly proclaims that Ashwathama is dead.

Drona knows that only Yudhisthira, with his firm adherence to the truth, could tell him for sure if his son had died. When Drona approaches Yudhisthira to seek to confirm this, Yudhisthira tells him that Ashwathama is dead..., then, ..the elephant, but this last part is drowned out by the sound of trumpets and conchshells being sounded as if in triumph, on Krishna's instruction.

Yudhisthira cannot make himself tell a lie, despite the fact that if Drona continued to fight, the Pandavas and the cause of dharma itself would lose. When he speaks his half-lie, Yudhisthira's feet and chariot descend to the ground momentarily. Drona is disheartened, and lays down his weapons. He is then killed by Dhristadyumna.

It is said that Drona's soul, by meditation had already left his body before Dhristadyumna could strike. His death greatly saddens Arjuna, who had hoped to capture him alive.

http://en.wikipedia.org/wiki/Drona

Clearly the Pandavas had an incentive to lie (as Laxmi does in our second example with Rayco), but Drona assumed that in the case of Yudhisthira, the loyalty to truth would override his self-interest. It so turned out that Drona was only partly right. 


\subsection{The two horsemen}

Suppose we want to find out which of two horses is faster. This is easy, we race them against each other. The horse which reaches the goal first is the faster horse. And surely this method should also tell us which horse is slower, it is the other one. However, there is a complication which will be instructive.

Two horsemen are on a forest path chatting about something. A passerby $M$, the mischief maker, comes along and having plenty of time and a desire for amusement, suggests that they race against each other to a tree a short distance away and he will give a prize of $\$ 100$. However, there is an interesting twist. He will give the $\$ 100$ to the owner of the slower horse. Let us call the two horsemen Bill and Joe. Joe's horse can go at 35 miles per hour, whereas Bill's horse can only go 30 miles per hour. Since Bill has the slower horse, he should get the $\$ 100$.

The two horsemen start, but soon realize that there is a problem. Each one is trying to go slower than the other and it is obvious that the race is not going to finish. There is a broad smile on the canny passerby's face as he sees that he is having some amusement at no cost.

Figure III, below, explains the difficulty. Here Bill is the row player and Joe is the column player. Each horseman can make his horse go at any speed

upto its maximum. But he has no reason to use the maximum. And in figure III, the left columns are dominant (yield a better payoff) for Joe and the top rows are dominant for Bill. Thus they end up in the top left hand corner, with both horses going at 0 miles per hour. 


\begin{tabular}{|c|c|c|c|c|c|}
\hline & 0 & 10 & 20 & 30 & 35 \\
\hline 0 & 0,0 & 100,0 & 100,0 & 100,0 & 100,0 \\
\hline 10 & 0,100 & 0,0 & 100,0 & 100,0 & 100,0 \\
\hline 20 & 0,100 & 0,100 & 0,0 & 100,0 & 100,0 \\
\hline 30 & 0,100 & 0,100 & 0,100 & 0,0 & 100,0 \\
\hline
\end{tabular}

Figure III

However, along comes another passerby, let us call her $S$, the problem solver, and the situation is explained to her. She turns out to have a clever solution. She advises the two men to switch horses. Now each man has an incentive to go fast, because by making his competitor's horse go faster, he is helping his own horse to 'win'!

Figure IV shows how the dominant strategies have changed. Now Joe (playing row) is better off to the bottom, and Bill playing column is better off to the right - they are both urging the horse they are riding (their opponent's horse) as fast as the horse can go. Thus they end up in the bottom right corner of figure IV. Joe's horse, ridden by Bill comes first and Bill gets the $\$ 100$ as he should. 


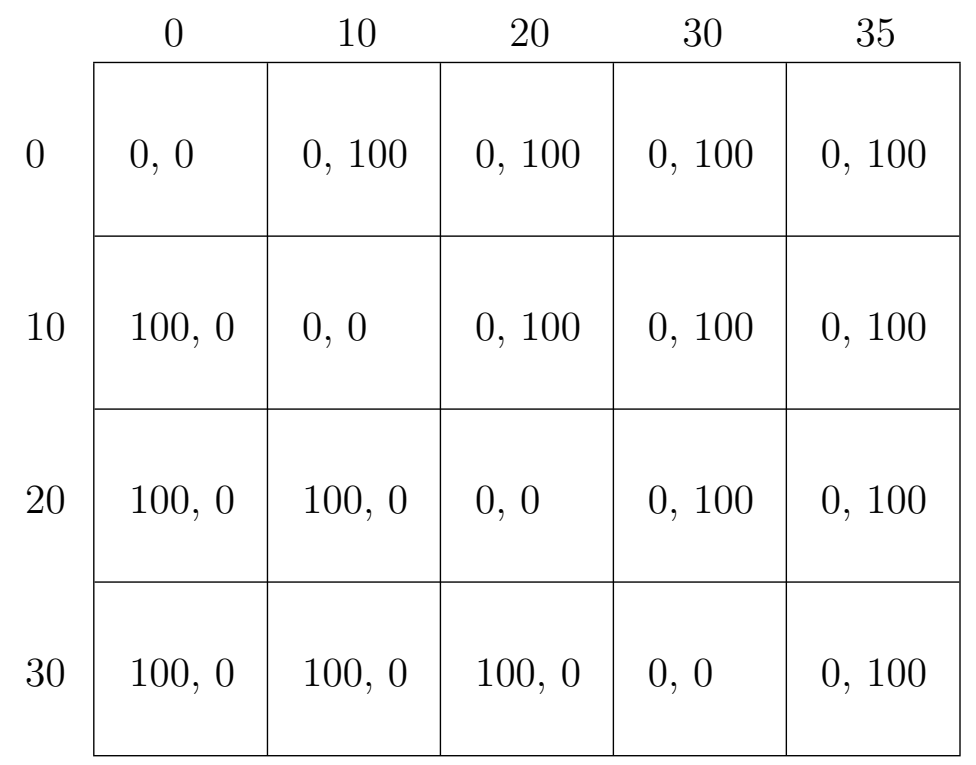

Figure IV

Of course, if the first passerby had really only wanted to reward the slower horse (or its owner) he could have done this without the horses being switched and for a little extra money. He could have kept quiet about the $\$ 100$ and offered a prize of $\$ 10$ to the owner of the faster horse. Then when the race was over, he would hand over the $\$ 10$ to Joe and $\$ 100$ to Bill. Here the effect would be achieved by hiding from the two horsemen what their best strategy was, and to fool them into thinking that some other action was in fact better.

While the problem of finding the faster horse, and that of finding the slower, are equivalent algorithmically, they are not equivalent game theoretically when the men ride their own horses. The equivalence is restored when the two men switch horses.

For a practical analogue of the two horses example, consider the issue of grades and letters of recommendation. Suppose that Prof. Meyer is writing a letter of recommendation for his student Maria and Prof. Shankar is writing one for his student Peter. Both believe that their respective students are good, but only good. Not very good, not excellent, just good. Both also know that only one student can get the job or scholarship. Under this circumstance, 
it is clear that both of the advisers are best off writing letters saying that their respective student is excellent. This is strategic behaviour in a domain familiar to all of us.

Sometimes employers will try to counter this by appealing to third parties for an evaluation, but the close knowledge that the two advisers have of their advisees cannot be discovered very easily.

Shankar's choices

\begin{tabular}{|c|c|c|c|c|}
\hline \multirow{4}{*}{$\begin{array}{l}\text { Meyer's } \\
\text { choices }\end{array}$} & & G & VG & $\mathrm{E}$ \\
\hline & G & $N J, N J$ & $N J, J$ & $N J, J$ \\
\hline & VG & $J, N J$ & $N J, N J$ & $N J, J$ \\
\hline & $\mathrm{E}$ & $J, N J$ & $J, N J$ & $N J, N J$ \\
\hline
\end{tabular}

Figure V

In Figure $\mathrm{V}$ above, $J$ represents job and $N J$ represents no job for the student. Then Meyer's lower strategies dominate his upper ones. And for Shankar, his rightward strategies dominate the strategies to the left. Hence, with each playing his dominant strategies, they end up in the lower right hand corner with neither student getting the job.

We do assume that in case of a tie neither student is hired. This of course need not be true in reality - perhaps one would be chosen at random. But if one of the students is actually superior, that information cannot be elicited by asking their advisers. Sometimes the National Science Foundation, giving out grants, tends to ask people to reveal their connections with various referees. Then some semblance of neutrality can be achieved. 


\subsection{A bankruptcy problem}

This problem has been studied by Aumann and Maschler [1].

A man dies leaving debts $d_{1}, \ldots, d_{n}$ totalling more than his estate $E$. How should the estate be divided among the creditors?

Here are some solutions from the Babylonian Talmud. In all cases, $n=$ $3, d_{1}=100, d_{2}=200, d_{3}=300$. Let the amounts actually awarded be $x_{1}, x_{2}, x_{3}$.

$E=100$.

The amounts awarded are $x_{i}=33.3$ for $i=1,2,3$

$E=200 . x_{1}=50, x_{2}=75, x_{3}=75$

$E=300 . x_{1}=50, x_{2}=100, x_{3}=150$.

What explains these numbers?

\section{The Contested Garment Principle}

Suppose two people $A, B$ are claiming 50 and 90 respectively from a debtor whose total worth is 100 . Then $A$ has conceded 50 and $B$ has conceded 10 . Then $B$ gets the 50 conceded by $A$ and $A$ gets the 10 conceded by $B$. That leaves 40 which is equally divided. Thus $A$ gets 30 and $B$ gets 70 .

Similarly, if $E$ is a garment, $A$ claims half of it and $B$ claims all, then $A$ ends up with .25 and $B$ with .75 of the garment.

Note that under the contested garment principle the results are monotonic in the claims and also in the total amount available for division.

Definition 2.1 $A$ bankrupcy problem is defined as a pair $E ; d$ where $d=$ $\left(d_{1}, \ldots, d_{n}\right), 0 \leq d_{1} \leq d_{2} \leq \ldots \leq d_{n}$ and $0 \leq E \leq d_{1}+\ldots d_{n}$. A solution to such a problem is an $n$-tuple $x=\left(x_{1}, \ldots, x_{n}\right)$ of real numbers with

$$
x_{1}+x_{2}+\ldots+x_{n}=E
$$

A solution is called CG-consistent if for all $i \neq j$, the division of $x_{i}+x_{j}$ prescribed by the contested garment principle for claims $d_{i}, d_{j}$ is $\left(x_{i}, x_{j}\right)$. 
Theorem 2.2 (Aumann, Maschler) Each bankrupcy problem has a unique consistent solution.

Proof (uniqueness) Suppose that $x, y$ are different solutions. Then there must be $i, j$ such that $i$ receives more in the second case and $j$ receives less. Assume wlog that $x_{i}+x_{j} \leq y_{i}+y_{j}$. Thus we have $x_{i}<y_{i}, x_{j}>y_{j}$ and $x_{i}+x_{j} \leq y_{i}+y_{j}$. But the monotonicity principle says that since $y_{i}+y_{j}$ is more, $j$ should receive more in the $y$ case. contradiction.

Acknowledgements: This research was partially supported by an internal research grant from PSC-CUNY. I thank Sonja Amadae and Andreas Witzel for comments.

\section{References}

[1] R. Aumann and M. Maschler, Game-theoretic analysis of a bankruptcy problem from the Talmud, J. Economic Theory, 36 (1985) 195-213.

[2] Joseph Farrell and Matthew Rabin, Cheap Talk, Journal of Economic Perspectives, 10 (1996) 103-118.

[3] Alan Gibbard, Manipulation of voting schemes: a general result, Econometrica, 41, No. 4 (1973), pp. 587-601.

[4] Garrett Hardin, The Tragedy of the Commons, Science, 162, No. 3859 (December 13, 1968), pp. 1243-1248.

[5] Martin Osborne and Ariel Rubinstein, A Course in Game Theory, MIT Press (1994)

[6] Rohit Parikh, Social Software, Synthese, 132, Sep 2002, 187-211.

[7] Mark A. Satterthwaite, Strategy-proofness and Arrow's Conditions: Existence and Correspondence Theorems for Voting Procedures and Social Welfare Functions, Journal of Economic Theory 10 (April 1975), 187-217.

[8] Alan D. Taylor, The manipulability of voting systems, The American Mathematical Monthly, April 2002. 